\title{
Out-of-home fish and chip consumption in the UK population
}

\author{
W.L. Wrieden, P. Mangwende and L. Goffe \\ Human Nutrition Research Centre and Institute of Health and Society, Newcastle University, Newcastle upon Tyne \\ NE2 $4 H H, U K$.
}

Out-of-home food, consisting of takeaway (TA) and eating out (EO) meal consumption has become an important and regular component of the Western diet ${ }^{(1)}$. Fish and chips constitute a high proportion of TA food $(39 \%)$ in the UK ${ }^{(2)}$ and are energy dense. High intakes of energy-dense foods coupled with low energy expenditure can lead to excess body weight and increased risk of type 2 diabetes, heart disease and cancer ${ }^{(3,4)}$.

This study aimed to assess UK "out-of-home" fish and chip consumption using frequency of purchase and mean per capita consumption as measures. Household food purchase data from the UK Living Costs and Food survey for years 2012 and 2013 were analysed to estimate total chips (made up of EO chips from fast-food outlet, EO chips with meals from restaurants or chip shops and TA chips), and total fish (made up of EO processed fish, TA fish, TA fish products and EO fish in batter or breadcrumbs) consumption. Household purchasing frequencies were determined together with mean per capita consumption (g per 14 day recording period) of the consuming households of out-of-home fish and out-of-home chips by simplified household composition, and quintiles of Equivalised Income (EI) (using the McClement's score) ${ }^{(5)}$. As the data is based on households a pragmatic decision was made to exclude children under 5 when calculating per capita consumption.

\begin{tabular}{|c|c|c|c|c|c|c|c|c|c|c|c|c|}
\hline \multirow[b]{3}{*}{ Year } & \multicolumn{6}{|c|}{$2012(n$ households 5569) } & \multicolumn{6}{|c|}{$2013(n$ households 5144) } \\
\hline & \multicolumn{3}{|c|}{ Fish } & \multicolumn{3}{|c|}{ Chips } & \multicolumn{3}{|c|}{ Fish } & \multicolumn{3}{|c|}{ Chips } \\
\hline & $\%$ & Mean & SD & $\%$ & Mean & $\mathrm{SD}$ & $\%$ & Mean & SD & $\%$ & Mean & SD \\
\hline \multicolumn{13}{|c|}{ Household composition: } \\
\hline One Man & $18 \cdot 3$ & 276 & 163 & $38 \cdot 1$ & 503 & 420 & $18 \cdot 1$ & 274 & 168 & $37 \cdot 3$ & 475 & 393 \\
\hline One Woman & $16 \cdot 6$ & 257 & 159 & $30 \cdot 7$ & 375 & 267 & $14 \cdot 2$ & 251 & 122 & $30 \cdot 5$ & 353 & 286 \\
\hline 2 Adults & $26 \cdot 3$ & 169 & 108 & $51 \cdot 0$ & 287 & 226 & $25 \cdot 6$ & 176 & 102 & $49 \cdot 9$ & 287 & 224 \\
\hline $3+$ Adults & $33 \cdot 9$ & 124 & $88 \cdot 9$ & $73 \cdot 0$ & 247 & 207 & 31.9 & 108 & $92 \cdot 0$ & 71.9 & 246 & 205 \\
\hline $\mathrm{H} /$ hold $\mathrm{w}$ children & $26 \cdot 1$ & 105 & $84 \cdot 2$ & $72 \cdot 4$ & 245 & 200 & $27 \cdot 4$ & 101 & $75 \cdot 3$ & $72 \cdot 4$ & 255 & 213 \\
\hline Single parents & $13 \cdot 7$ & 123 & $84 \cdot 5$ & $60 \cdot 5$ & 327 & 314 & $14 \cdot 2$ & 127 & 93.4 & $57 \cdot 3$ & 269 & 238 \\
\hline \multicolumn{13}{|l|}{ EI quintile: } \\
\hline Lowest income & $16 \cdot 4$ & 167 & 122 & $45 \cdot 5$ & 321 & 296 & $14 \cdot 3$ & 200 & 146 & $40 \cdot 9$ & 299 & 276 \\
\hline Highest income & $29 \cdot 0$ & 162 & 129 & $57 \cdot 9$ & 290 & 256 & $28 \cdot 1$ & 153 & 105 & $58 \cdot 2$ & 299 & 257 \\
\hline
\end{tabular}

Significant differences $(P<0.001$ using Chi-Square) were found for the proportion of households purchasing fish and chips based on the household composition, and by EI. In summary, it was found that a higher proportion of those in the highest income quintile purchased out-of-home fish and chips but they had a similar per capita consumption to those in the lowest income quintile (except in 2013 for fish). Single person households had a higher per capita consumption compared with those households with more than one adult but a lower proportion of households purchasing. Out-of-home fish and chips constitute a relatively small proportion of the diet in the UK (approximately $4 \%$ of energy for average consumers) so interventions to improve their nutrient profile or decrease consumption in isolation are unlikely to have an impact on overall obesity rates.

Data provided by the UK Data Archive.

1. Orfanos P, Naska A, Trichopoulos D et al. (2007). Public Health Nutr 10, 1515-1525.

2. Mintel (2012). Mintel re-runs first ever consumer report from 1972 to celebrate 40th anniversary. Available at: http://www.mintel.com/press-centre/ mintel-corporate/mintel-re-runs-first-ever-consumer-report-from-1972-to-celebrate-40th-anniversary (accessed 10 March 2016).

3. Prentice AM, Jebb SA. (2003) Obes Rev 4, 187-194.

4. World Cancer Research Fund/American Institute for Cancer Research (2007) Food, nutrition, physical activity and the prevention of cancer: a global perspective. Washington DC: American Institute for Cancer Research.

5. McClements D. (1977) Journal Public Econ 8, 191-210. 